\title{
The prpE gene of Salmonella typhimurium LT2 encodes propionyl-CoA synthetase
}

\author{
Alexander R. Horswill and Jorge C. Escalante-Semerena
}

Department of Bacteriology, University of WisconsinMadison, 1550 Linden Drive, Madison, WI 53706-1567, USA

\author{
Author for correspondence: Jorge C. Escalante-Semerena. Tel: +1608 2627379 . Fax: +1 6082629865 . \\ e-mail : jcescala@facstaff.wisc.edu
}

\begin{abstract}
Biochemical and genetic evidence is presented to demonstrate that the prpE gene of Salmonella typhimurium encodes propionyl-CoA synthetase, an enzyme required for the catabolism of propionate in this bacterium. While prpE mutants used propionate as carbon and energy source, prpE mutants that lacked acetyl-CoA synthetase (encoded by acs) did not, indicating that Acs can compensate for the lack of PrpE in prpE mutants. Cell-free extracts enriched for PrpE catalysed the formation of propionyl-CoA in a propionate-, ATP-, $\mathrm{Mg}^{2+}$ and HS-COA dependent manner. Acetate substituted for propionate in the reaction at $48 \%$ the rate of propionate; butyrate was not a substrate for PrpE. The propionyl-CoA synthetase activity of PrpE was specific for ATP. GTP, ITP, CTP and TTP were not used as substrates by the enzyme. UV-visible spectrophotometry, HPLC and MS data demonstrated that propionyl-CoA was the product of the reaction catalysed by PrpE.
\end{abstract}

Keywords: propionyl-CoA synthetase, short-chain fatty acid catabolism, 2-methylcitric acid cycle enzymes, propionate catabolic genes

\section{INTRODUCTION}

Growth of Salmonella typhimurium on propionate as a sole carbon and energy source requires enzymes encoded by the prp locus (Hammelman et al., 1996; Horswill \& Escalante-Semerena, 1997). Five genes, prpRBCDE, make up this locus and four of these genes show DNA and amino acid sequence similarity to proteins with known biochemical activities (Fig. 1). PrpR is a member of the family of RpoN $\left(\sigma^{54}\right)$ activators; $\operatorname{PrpB}$ is homologous to isocitrate lyases; PrpC is homologous to citrate synthases; and PrpE is homologous to acetylCoA synthetases. A similar region in Escherichia coli has recently been implicated in the breakdown of propionate by the methylcitric acid cycle and the PrpC homologue has been identified as methylcitrate synthase (Gerike et al., 1998; Textor et al., 1997). We have obtained evidence that $S$. typhimurium also catabolizes propionate via this pathway (data to be presented elsewhere).

The activation of propionate to propionyl-CoA is the proposed first step of the methylcitric acid cycle and of all other propionate breakdown pathways in bacteria (Horswill \& Escalante-Semerena, 1997; Textor et al., 1997). However, no evidence has been reported identi-

Abbreviations: $\mathrm{Ap}$, ampicillin; $\mathrm{Cm}$, chloramphenicol; $\mathrm{Km}$, kanamycin; $\mathrm{Tc}$, tetracycline. fying a gene encoding propionyl-CoA synthetase (EC 6.2.1.17) activity. This activity has been attributed to the two routes of acetyl-CoA synthesis (Rhie \& Dennis, 1995a, b; Van Dyk \& LaRossa, 1987), i.e. the acetate kinase (AckA) and phosphotransacetylase (Pta) pathway, and the acetyl-CoA synthetase (Acs) pathway. In a previous paper, we proposed that PrpE catalysed the synthesis of propionyl-CoA during propionate breakdown (Horswill \& Escalante-Semerena, 1997). However, no evidence to support this hypothesis was presented. The location of $p r p E$ downstream of the $\operatorname{prp} B C D$ operon strongly suggested that the putative propionyl-CoA synthetase activity was needed. Failure to isolate $p r p E$ mutants was attributed to the existence of an enzyme that can substitute for PrpE during growth on this carbon source (Horswill \& Escalante-Semerena, 1997).

In this paper, we address the function of $\operatorname{PrpE}$ by demonstrating that: (i) $\operatorname{prpE}$ is part of the $\operatorname{prp} B C D$ operon; (ii) acetyl-CoA synthetase compensates for lack of PrpE; and (iii) PrpE has propionyl-CoA synthetase activity.

\section{METHODS}

Culture media and growth conditions. Growth of $S$. typhimurium in rich and minimal media and the concentration of antibiotics were as described previously (EscalanteSemerena \& Roth, 1987). The final concentrations of 
(a)

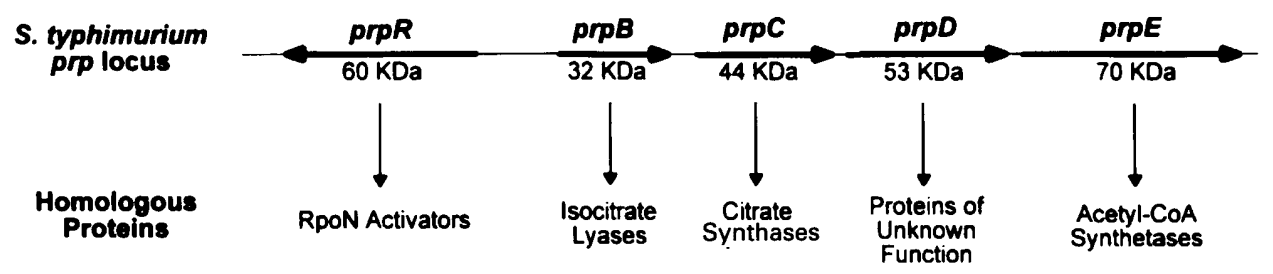

(b)

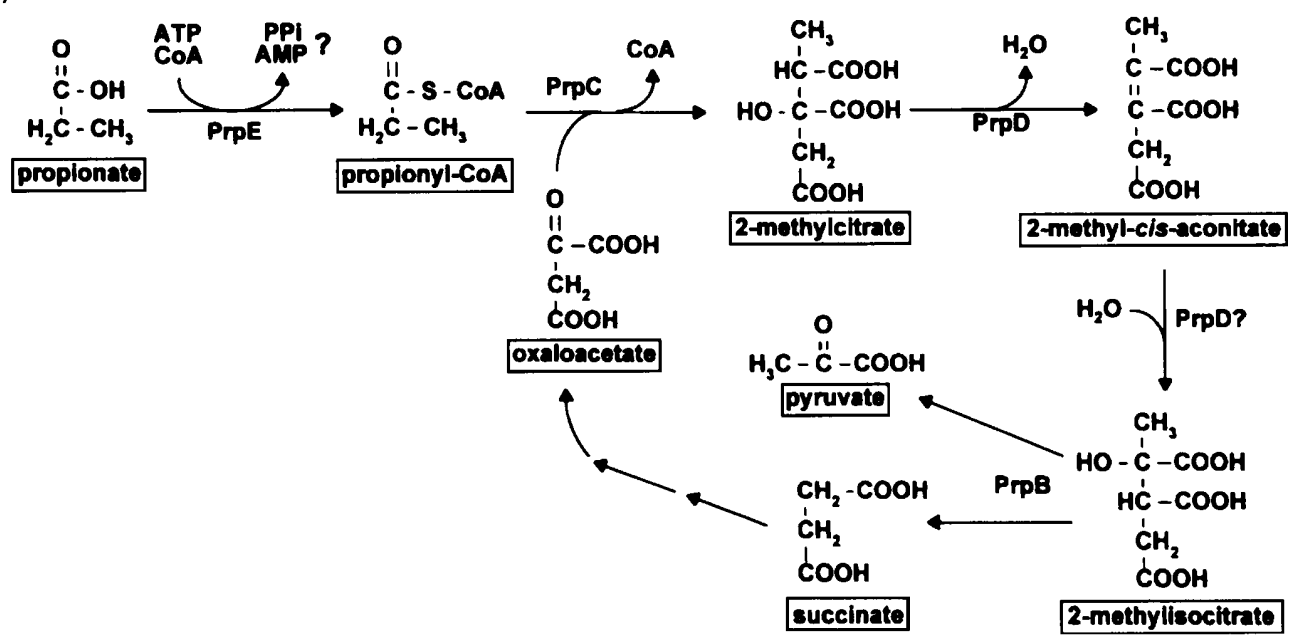

Fig. 1. The prpRBCDE locus and methylcitric acid cycle of $S$. typhimurium. (a) Graphical representation of the prp locus showing homologues and predicted molecular mass of each protein (Horswill \& Escalante-Semerena, 1997). (b) Propionate breakdown via the methylcitric acid cycle with the steps catalysed by proteins of the prp locus. Evidence for the assignment of PrpB, PrpC and PrpD catabolic steps will be presented elsewhere.

compounds provided in the culture medium were as follows: methionine, $0.5 \mathrm{mM}$; propionate, $30 \mathrm{mM}$; acetate, $10 \mathrm{mM}$. All chemicals were purchased from Sigma unless otherwise stated. Overnight cultures of strains grown in nutrient broth (NB) were subcultured 1:50 (v/v) into $5 \mathrm{ml}$ minimal medium with appropriate supplements. Cultures were incubated in $18 \times 150 \mathrm{~mm}$ tubes at $37^{\circ} \mathrm{C}$ with shaking, and cell growth was monitored at $650 \mathrm{~nm}$ with a Spectronic 20D spectrophotometer furnished with a red filter (Milton Roy). A list of strains and plasmids used and their genotypes is provided in Table 1.

Overexpression of prpE. Strain JE4184 (pGP1-2 rpo ${ }^{+} \mathrm{kan}^{+}$; pPRP38 $\left.p r p E^{+} b l a^{+}\right)$was used to overexpress $p r p E$ using the temperature-sensitive T7 system of Tabor (1990). Cell pellets were stored at $4{ }^{\circ} \mathrm{C}$ for no longer than $16 \mathrm{~h}$ before use.

Genetic crosses. Transductions involving phage P22 HT105 int201 were performed as described by Chan et al. (1972), Schmieger (1971) and Schmieger \& Bakhaus (1973). Transductions from E. coli into $S$. typhimurium involving phage P1 were performed as reported by O'Brien et al. (1992).

Recombinant DNA techniques. Restriction and modification enzymes were purchased from Promega unless otherwise stated and were used according to the manufacturer's instructions. All DNA manipulations were performed in $E$. coli $\mathrm{DH} 5 \alpha / \mathrm{F}^{\prime}$. Plasmids were transformed into $E$. coli or $S$. typhimurium by $\mathrm{CaCl}_{2}$ heat-shock as described by Ausubel $e t$ al. (1989). Plasmids transferred to S. typhimurium were first transformed into recombination-deficient $S$. typhimurium strain JR501 (Tsai et al., 1989). Plasmids from strain JR501 were quick-transformed into other $S$. typhimurium strains as described by Ryu \& Hartin (1990).

Plasmid constructions. Plasmid pPRP37: a $3 \mathrm{~kb}$ HindIII-SphI fragment of pPRP29 containing the $p r p E^{+}$gene was ligated into pSU20 $\mathrm{cat}^{+}\left(\mathrm{Cm}^{\mathrm{r}}\right)$ (Bartolomé et al., 1991) digested with the same enzymes. Plasmid pPRP38: a $3 \mathrm{~kb}$ BamHI-HindIII fragment of plasmid pPRP37 $\mathrm{cat}^{+}\left(\mathrm{Cm}^{\mathrm{r}}\right)$ was cloned into plasmid pT7-6 bla ${ }^{+}\left(\mathrm{Ap}^{\mathrm{r}}\right)$ (Tabor, 1990) cut with the same enzymes. Plasmid pPRP45: a $2 \mathrm{~kb}$ NdeI-Clal fragment containing the $\operatorname{prpE^{+}}$ gene was ligated into pT7-7 bla $\left(\mathrm{Ap}^{\mathrm{r}}\right)$ (Tabor, 1990) digested with the same enzymes. The NdeI site was constructed by PCR mutagenesis at the ATG start codon of $p r p E$ to allow use of the T7 ribosome-binding site. Plasmid pPRP49: a 350 bp HindIII-SalI fragment of plasmid pPRP37 cat $^{+}\left(\mathrm{Cm}^{\mathrm{r}}\right)$ was cloned into plasmid pMAK705 $\mathrm{cat}^{+}\left(\mathrm{Cm}^{\mathrm{r}}\right)$ (Hamilton et al., 1989) digested with the same enzymes. Plasmid pPRP50: a $1.3 \mathrm{~kb}$ PstI fragment of plasmid pUC4K (Pharmacia) containing the kanamycin $(\mathrm{Km})$ resistance gene was blunt-ended with Klenow fragment of DNA polymerase I and ligated into Sfil-digested plasmid pPRP49. Plasmid pPRP51: an approximately $2.5 \mathrm{~kb}$ Smal fragment from

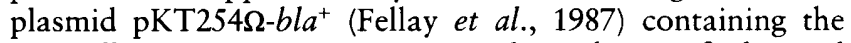
ampicillin (Ap) resistance gene was ligated into SfiI-digested plasmid pPRP49. Plasmid pPRP54: plasmid pPRP37 prp $E^{+}$ $\mathrm{cat}^{+}\left(\mathrm{Cm}^{\mathrm{r}}\right)$ was digested with HindIII, blunt-ended with Klenow fragment and then digested with $S p h$ I. The approximately $3 \mathrm{~kb}$ fragment containing the $p r p E$ gene was cloned into plasmid pBAD30 $\left(b^{\prime} a^{+}\right)$(Guzman et al., 1995) digested with $S m a I$ and $S p h I$. 
Table 1. Strains and plasmids used

\begin{tabular}{|c|c|c|}
\hline Strain or plasmid & Genotype & Reference or source* \\
\hline \multicolumn{3}{|l|}{ E. coli } \\
\hline AJW805 & $\begin{array}{l}\text { NlacX74 thi-1 thr-1(amber) leuB6 metF159(amber) } \\
\quad \text { rpsL136 ilacY acs::kan-1 }\end{array}$ & A. Wolfe ${ }^{1}$ \\
\hline $\mathrm{DH} 5 \alpha / \mathrm{F}^{\prime}$ & $\begin{array}{l}\mathrm{F}^{\prime} \text { endA1 hsdR17 }\left(\mathrm{r}_{\mathrm{k}}^{-} \mathrm{m}_{\mathrm{k}}^{+}\right) \text {supE44 thi-1 recA1 gyrA } \\
\left.(\mathrm{Nal})^{\mathrm{r}}\right) \text { relA1 } \Delta(\text { lacZYA-argF }) \text { U169 deoR } \\
{[\phi 80 \mathrm{~d} \text { lac }(\text { lacZ }) M 15]}\end{array}$ & New England Biolabs \\
\hline \multicolumn{3}{|l|}{ S. typhimurium $†$} \\
\hline JR501 & $\begin{array}{l}\text { hsdSA29 hsdSB121 hsdL6 metA22 metE551 trpC2 } \\
\text { ilv-452 rpsL120 xyl-404 galE719 H1-b H2-en,n,x } \\
\text { (Fels2-) fla-66 nml }\end{array}$ & Tsai et al. (1989) \\
\hline MS1933 & $\begin{array}{l}\text { mutS: : Tn10 galE496 metA22 metE55 xyl-404 } \\
\text { (Fels2-) H1-b nml H2 enx ilv hsdL6 hsdSA29 } \\
\text { rpsL120 }\end{array}$ & $\begin{array}{l}\text { S. Maloy via } \\
\text { D. Downs }\end{array}$ \\
\hline TR6583 & metE205 ara-9 & $\begin{array}{l}\text { K. Sanderson via } \\
\text { J. Roth }\end{array}$ \\
\hline \multicolumn{3}{|c|}{ Derivatives of TR6583 } \\
\hline JE4182 & TR6583/pGP1-2 (T7 rpo $\left.o^{+} \mathrm{kan}^{+}\right)$ & This work \\
\hline JE4184 & $\begin{array}{l}\left.\text { TR6583/pGP1-2 (T7 rpo }{ }^{+} k a n^{+}\right) \text {pPRP38 }\left(p r p E^{+}\right. \\
\left.b l a^{+}\right)\end{array}$ & This work \\
\hline JE4271 & TR6583/pBAD30 $b_{l a}^{+}$ & This work \\
\hline JE4287 & TR6583/pGP1-2 (T7 rpo kan $^{+}$) pT7-6 bla $^{+}$ & This work \\
\hline JE4288 & acs::kan-1 & This work \\
\hline JE4289 & prpE212::bla acs::kan-1 & This work \\
\hline JE4305 & acs::kan-1 nrfA1:: Tn10d(Tc) & This work \\
\hline JE4312 & $\Delta 1231$ (acs) & This work \\
\hline JE4354 & JE3056/pPRP12-5.4 $\left[p r p B C D^{+} k a n^{+}\right]$ & This work \\
\hline JE4358 & JE4336/pPRP12-5.4 $\left[\right.$ prpBCD $\left.{ }^{+} \mathrm{kan}^{+}\right]$ & This work \\
\hline \multicolumn{3}{|l|}{ Plasmids } \\
\hline pPRP29 & $\begin{array}{l}\operatorname{prpBCDE^{+}} \text { cloned into pBR328 }\left[\text { bla }^{+} c a t^{+}\left(\mathrm{Ap}^{\mathrm{r}} \text {, }\right.\right. \\
\left.\left.\mathrm{Cm}^{\mathrm{r}}\right)\right]\end{array}$ & Laboratory collection \\
\hline pPRP12-5.4 & $\operatorname{prpBCD^{+}}$ in $\mathrm{pSU} 39 ; \mathrm{kan}^{+}$ & Laboratory collection \\
\hline
\end{tabular}

*1, Loyola University, Chicago, USA ; 2, University of Wisconsin-Madison, USA ; 3, University of Utah, USA.

†All S. typhimurium strains are derivatives of LT2.

Construction of prpE insertions and deletions. Plasmids pPRP50 and pPRP51 were transformed into S. typhimurium T'R6583 $\left(p r p E^{+}\right)$and cointegrates were isolated and resolved as described by Hamilton et al. (1989). To isolate strains carrying $p r p E$ insertions from plasmid-containing strains, P22 phage grown on a pool of 10 independently resolved cointegrates was used as donor to transduce strain TR6583 to Ap or Km resistance. P22 crosses were plated on NB with $\mathrm{Km}$ for pPRP5() and NB with Ap for pPRP51, and incubated at $44{ }^{\circ} \mathrm{C}$. $\mathrm{Km}^{\mathrm{r}} \mathrm{Cm}^{*}$ (for pPRP50) and $\mathrm{Ap}^{\mathrm{r}} \mathrm{Cm}^{\mathrm{s}}$ (for pPRP51) transductants were saved for further analysis. A strain carrying insertion nrfA1::Tn10 $16 \Delta 17$ (hereafter referred to as $\operatorname{Tn} 10 d\left(T_{c}\right)$; Way et al., 1984) was used to isolate an acs deletion by the method of Bochner et al. (1980) as modified by Maloy \& Nunn (1981). A Km $\mathrm{Tc}^{\mathrm{s}} \mathrm{Ace}^{-}$(JE4312) strain was isolated and saved for further experiments.

Sequencing of prpE insertions. The location of the Ap- and Kmresistance cassettes within $p r p E$ was verified by PCR amplification and sequencing. PCR reactions were prepared using one-tenth volume of boiled template, 50 pmol of each primer,
$0.2 \mathrm{mM}$ of each dNTP (Promega) and Pfu DNA polymerase (Stratagene) according to the manufacturer's instructions. Reactions were performed in a GeneAmp PCR System 2400 (Perkin Elmer) using the following conditions: 30 cycles at $94^{\circ} \mathrm{C}$ for $90 \mathrm{~s}, 50^{\circ} \mathrm{C}$ for $30 \mathrm{~s}, 72^{\circ} \mathrm{C}$ for $2 \mathrm{~min}$. The $S^{\prime}$ and $3^{\prime}$ ends of the prpE212::bla+ insertion were PCR-amplified independently using the following sets of primers: $5^{\prime}$-CGTGGAGTTTACTGATGGAT-3' (in $p r p D$ ) and 5'-GCATCTTTTACTTTCACCAGCG-3' (in the bla gene) to generate a $1.5 \mathrm{~kb}$ fragment; 5'-ATGGATGAACGAAATAGACAGA-3' (in the bla gene) and $5^{\prime}$-GCTCTTCATCGGTCTCTGA-3' (in prpE) to generate a $1.4 \mathrm{~kb}$ fragment. For prpE213::kan the entire $\mathrm{Km}^{\mathrm{r}}$ cassette and flanking DNA was amplified as a $1.8 \mathrm{~kb}$ fragment using the $\operatorname{prpD}$ and $p r p E$ primers shown above. Amplified DNA was purified using the QIAquick PCR Purification kit (Qiagen). PCR sequencing reactions were prepared using the ABI PRISM Dye Terminator Cycle Sequencing kit (Perkin-Elmer) according to the manufacturer's instructions. Reactions were purified in AutoSeq G-50 columns (Pharmacia Biotech), dried in a SpeedVac concen- 
trator (Savant Instruments) and sequenced at the Biotechnology Center (University of Wisconsin-Madison, USA).

Sequencing of the acs::kan-1 insertion. Strain JE4305 [acs : : kan-1 $n r f A 1:: \operatorname{Tn} 10 d(\mathrm{Tc})]$ was used to locate the $\mathrm{Km}$ resistance cassette in acetyl-CoA synthetase. Primers 5'-TCCATTGCTGTTGACAAAGG-3' for Tn10-L and 5'-ACCCATATAAATCAGCATCC- $3^{\prime}$ for the $\mathrm{Km}$ resistance cassette were used to PCR-amplify the chromosomal DNA between the two insertions. The PCR amplification procedure used to locate prpE insertions (described above) was also used to amplify a $2 \mathrm{~kb}$ DNA fragment between the acs and $n r f A$ insertions. Sequence was obtained (as described above) for both ends of the amplified DNA fragment.

\section{Biochemical and spectroscopic techniques}

Preparation of dialysed, cell-free extracts. Cell pellets of strain JE4184 grown as described above were resuspended in $40 \mathrm{ml}$ cold, $50 \mathrm{mM}$ potassium phosphate buffer $(\mathrm{pH} 7.5)$ and the suspensions were centrifuged at $10500 \mathrm{~g}$ for $10 \mathrm{~min}$ at $4{ }^{\circ} \mathrm{C}$. The pellet was resuspended in $40 \mathrm{ml}$ phosphate buffer, centrifuged as before and resuspended again in $10 \mathrm{ml}$ phosphate buffer. Cells were kept on ice and broken by sonication (10 min, $50 \%$ duty, setting 3 ) on a model 550 Sonic Dismembrator (Fisher Scientific). Cell debris was removed by centrifugation in $50 \mathrm{ml}$ Nalgene polypropylene copolymer Oakridge tubes (Fisher Scientific) at $31000 \mathrm{~g}$ for $1 \mathrm{~h}$ at $4{ }^{\circ} \mathrm{C}$. The supernatant was dialysed at $4{ }^{\circ} \mathrm{C}$ in Spectra/Por 1 Molecularporous dialysis membrane (Spectrum Medical Industries) against 11 phosphate buffer $\left(50 \mathrm{mM}, \mathrm{pH} 7 \cdot 5,4{ }^{\circ} \mathrm{C}\right)$. The dialysis buffer was replaced after 2 and $4 \mathrm{~h}$ and then allowed to dialyse an additional $16 \mathrm{~h}$. The extracts $(6 \mathrm{mg}$ protein $\mathrm{ml}^{-1}$ ) were maintained at $4{ }^{\circ} \mathrm{C}$ for up to 1 week with no detectable loss of activity. Strain JE4287 (pGP1-2 rpo+ $\mathrm{kan}^{+}$; pT7-6 $\left.b l a^{+}\right)$was used to establish the background acyl-CoA synthetase activity in our in vitro assays. Increases in this activity seen in extracts of strain JE4184 were relative to the ones measured for extracts of strain JE4287.

In vitro acyl-COA synthetase assay. The assay described by Brown et al. (1977) was used to monitor the PrpE-dependent synthesis of acyl-CoA compounds. The following were combined in a $1.5 \mathrm{ml}$ reaction volume: $\mathrm{HS}-\mathrm{CoA}, 0.75 \mu \mathrm{mol}$; ATP, $1.5 \mu \mathrm{mol}$; $\mathrm{MgCl}_{2}, 7 \cdot 5 \mu \mathrm{mol}$; hydroxylamine, $450 \mu \mathrm{mol}$; crude cell-free extract, $30 \mu \mathrm{g}$; phosphate buffer, $75 \mu \mathrm{mol}, \mathrm{pH} 7 \cdot 5$. The mixture was preincubated at $37^{\circ} \mathrm{C}$ for $10 \mathrm{~min}$ and the reaction was started with propionate $(7.5 \mu \mathrm{mol})$. The reaction mixture was incubated at $37^{\circ} \mathrm{C}$ for $30 \mathrm{~min}$ and was stopped with $1.5 \mathrm{ml} 2.0 \% \mathrm{FeCl}_{3} / 4.0 \%$ trichloroacetic acid $/ 2 \mathrm{M} \mathrm{HCl}$ reagent. A reaction mixture without $\mathrm{HS}$-CoA was prepared as control for each condition tested. Colour was allowed to develop for at least $10 \mathrm{~min}$ but no longer than $45 \mathrm{~min}$. Absorbance at $520 \mathrm{~nm}$ was measured using the no HS-CoA controls as blanks. Detection of product was linear for $30 \mathrm{~min}$ under these assay conditions. To assess the substrate specificity of PrpE, acetate and butyrate were substituted for propionate at an equal concentration. Similarly, GTP, ITP, CTP and TTP were substituted for ATP at an equimolar concentration. Standard curves were prepared for the assay using propionylCoA, acetyl-CoA and butyryl-CoA. A unit of activity (U) was defined as the amount of enzyme required for the synthesis of $1 \mu \mathrm{mol}$ acyl-CoA $\mathrm{min}^{-1}$.

Chromatography and spectroscopy. For HPLC analysis of the PrpE reaction, we used a modification of the procedure described by Hosokawa et al. (1986) to separate propionylCoA from reaction mixture substrates. The reaction mixture was resolved using reverse-phase HPLC with a Prodigy 5 ODS- 2 column $(250 \times 4.60 \mathrm{~mm}$; Phenomenex $)$. The column was developed immediately after injection of the sample with an $80 \mathrm{~min}$ convex gradient (Waters curve 3) of acetonitrile/water $(10: 90)$ containing $0.2 \mathrm{M}$ ammonium acet-

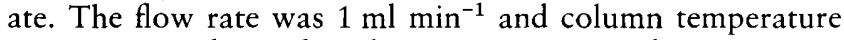
was maintained at $35^{\circ} \mathrm{C}$. Elution was monitored at $260 \mathrm{~nm}$ on a Waters model 990 Plus photodiode array detector (Millipore).

For MS of the PrpE product, HPLC fractions containing the PrpE product were combined and solvent was removed in a SpeedVac concentrator. Negative ion electrospray spectra were obtained by resuspending samples in $50 \%$ acetonitrile and analysing them with a Perkin Elmer Sciex API 365 triple quadrupole spectrometer equipped with an ion spray source. Authentic propionyl-CoA (Sigma) was subjected to the same manipulations and used as positive control.

Other procedures. Protein concentrations were determined by the method described by Kunitz (1952). Proteins were separated by SDS-PAGE (Laemmli, 1970) using $12 \%$ polyacrylamide gels and were visualized with Coomassie blue (Sasse, 1991). Low-range standards (14-97.4 kDa) were used for SDS-PAGE (Bio-Rad). UV-visible spectroscopy was performed in a computer-controlled Lambda $6 \mathrm{UV}$-vis spectrophotometer (Perkin-Elmer).

\section{RESULTS AND DISCUSSION}

\section{Construction and analysis of prpE mutants}

Chromosomal insertions prpE212::bla and prpE213::kan were constructed by gene replacement and the location of both antibiotic markers within $p r p E$ was verified by sequencing. On propionate medium, $\operatorname{prp} E$ mutants and the $p r p E^{+}$strain grew with very similar doubling times, i.e. $6 \cdot 6 \mathrm{~h}$ for the mutant and $6 \cdot 1 \mathrm{~h}$ for the wild-type. This result suggested that an alternative function compensated for the lack of PrpE. Since bacterial acetyl-CoA synthetases often activate propionate (Maruyama, 1982; Preston et al., 1990; Priefert \& Steinbüchel, 1992), we inactivated the acs gene which encodes acetyl-CoA synthetase. An E. coli acs::kan-1 insertion was moved into S. typhimurium (Kumari et al., 1995 ) and the location of the $\mathrm{Km}$ resistance cassette was verified by PCR amplification of chromosomal DNA between acs::kan-1 and $n r f A 1:: \operatorname{Tn} 10 d(\mathrm{Tc})$ in strain JE4305, followed by sequencing of the amplified DNA. The acs mutant JE4288 grew in propionate medium with a doubling time of $6 \cdot 2 \mathrm{~h}$. However, the acs prpE double mutant strain JE4289 failed to grow on propionate. Plasmid pPRP54 $\left(\mathrm{P}_{B A D^{-}}\right.$prp $\left.E^{+}\right)$allowed strain JE4313 (metE205 ara-9 $\Delta 1231$ acs prpE213:: $\mathrm{kan}^{+}$) to grow in propionate medium containing arabinose with a doubling time of $8.3 \mathrm{~h}$. This rate of growth was identical to the one measured for the $a c s^{+}$prp $E^{+}$strain JE4271. Plasmid pPRP54 also complemented growth of acs mutants on low acetate $(10 \mathrm{mM})$ when arabinose was included in the medium, indicating that $\operatorname{PrpE}$ can synthesize acetyl-CoA.

On the basis of these data we conclude that acetyl-CoA synthetase can compensate for the lack of propionylCoA synthetase activity in $\operatorname{prpE}$ mutants. PrpE and Acs appear to be the only propionyl-CoA synthetase activities in the cell capable of supporting growth on propionate. 


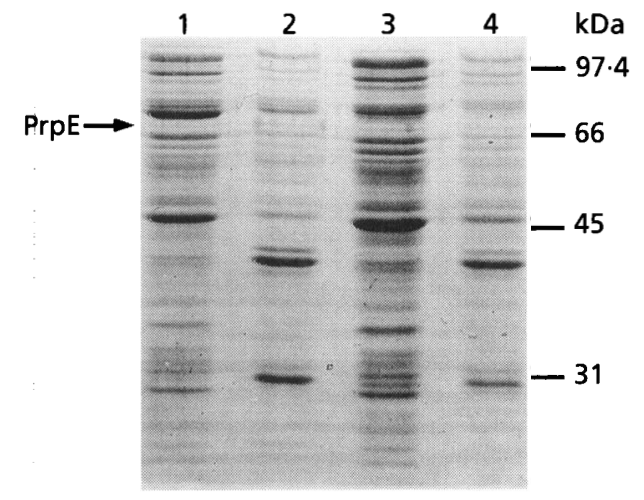

Fig. 2. Overexpression of prpE. Lanes: 1 and 2, prpE overexpression strain (JE4184); 3 and 4, control strain with no prpE insert (JE4287); 1 and 3, dialysed, soluble extract from each strain; 2 and 4, insoluble protein from each strain. Each lane contained approximately $5 \mu \mathrm{g}$ protein. Numbers on the right indicate the molecular mass of the following proteins (top to bottom): $\beta$-phosphorylase, serum albumin, ovalbumin and carbonic anhydrase.

In $S$. typhimurium, the acetate kinase (ackA) and phosphotransacetylase ( $p t a)$ pathway of acetyl-CoA synthesis does not appear to be a major contributor (if at all) to the synthesis of propionyl-CoA, since ackA mutantsi of this bacterium are not affected in their ability to grow on propionate (data not shown). These results are consistent with reports that propionate is not a substrate for AckA (Fox \& Roseman, 1986).

\section{prpE is part of the prp operon}

To determine if $\operatorname{pr} p E$ was cotranscribed with $\operatorname{pr} p B C D$, the polarity of a $\operatorname{prpB}$ insertion on $\operatorname{prp} E$ was assessed. For this purpose, plasmid pPRP12-5.4 (Horswill \& Escalante-Semerena, 1997) was introduced into a tester strain lacking Acs. When the growth of strains JE4354 $(\operatorname{prpB121}:: \operatorname{Tn} 10 d(\mathrm{Tc}) / \mathrm{pPRP12}-5.4)$ and JE4358 (prpB121:: Tn10d(Tc) $\Delta 1231$ (acs)/pPRP12-5.4) was compared, strain JE4358 failed to utilize propionate as carbon and energy source. The polar effect of the

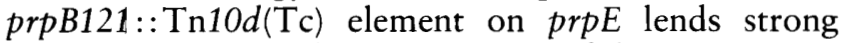
support to the idea that $p r p E$ is part of the prp operon.

\section{Overexpression of prpE}

PlasmidipPRP38 was used to overexpress prpE. Plasmids pPRP38 or pT7-6 (vector-only control) were each transformed into strain JE4182, which carried plasmid pGP1-2 (Tabor, 1990), resulting in strains JE4184 (pPRP38, pGP1-2) and JE4287 (pT7-6, pGP1-2), respectively. These strains were grown under conditions that overexpressed $\operatorname{pr} p E$ and dialysed cell-free extracts of each strain were prepared. Cell-free extracts were fractionated by centrifugation and samples (approx. $5 \mu \mathrm{g}$ of soluble and insoluble protein) were analysed by SDS-PAGE (Fig. 2). PrpE was identified as the $70 \mathrm{kDa}$ band (lane 1) that was absent in the control strain (lanes
Table 2. PrpE activity and substrate specificity in dialysed, crude cell-free extracts

\begin{tabular}{|lcr|}
\hline Assay conditions & $\begin{array}{c}\text { Specific } \\
\text { activity } \\
{\left[\mathrm{mU}\left(\mathbf{m g}^{\text {protein }}\right)^{-1}\right]^{*}}\end{array}$ & $\begin{array}{c}\text { Relative } \\
\text { activity } \\
(\%) \dagger\end{array}$ \\
\hline Complete & 630 & 100 \\
- ATP & 25 & 4 \\
- Mg ${ }^{2+}$ & 92 & 15 \\
- Propionate & 30 & 5 \\
- PrpE & 23 & 4 \\
Complete with acetate $\neq$ & 300 & 48 \\
Complete with butyrate $\$$ & 17 & 3 \\
pT7-6 with propionate $\|$ & 28 & 4 \\
pT7-6 with acetate $\|$ & 52 & 8 \\
\hline
\end{tabular}

*A unit of activity (U) is defined as the amount of enzyme that generates $2 \mu \mathrm{mol}$ product $\mathrm{min}^{-1}$.

†Relative activities were determined by dividing specific activities by that of the PrpE reaction with propionate $[630 \mathrm{mU}$ (mg protein $)^{-1}$.

$\ddagger$ Acetate substituted for propionate.

$\$$ Butyrate substituted for propionate.

I An equal amount of dialysed cell-free extract of strain JE4287 (vector-only control) was substituted for cell-free extract of the prp $E^{+}$-overexpressing strain JE4184.

3 and 4). Under these overexpression conditions, PrpE remained mostly soluble, however a small amount was lost as inclusion bodies (lane 2). Overexpression of prpE to higher levels using plasmid pPRP45 ( $p r p E^{+}$in pT7-7) with the T7 ribosome-binding site resulted only in a large increase of insoluble protein (data not shown).

\section{Acyl-CoA synthetase activity}

Table 2 presents data which demonstrate that PrpE has acyl-CoA synthetase activity. Enzyme activity depended upon the addition of propionate or acetate, HS-CoA, ATP, $\mathrm{Mg}^{2+}$ and PrpE present in crude cell-free extract. Propionate was the preferred substrate of PrpE. The activity of the enzyme with propionate as substrate was assigned the arbitrary value of $100 \%$. PrpE synthesized acetyl-CoA at $48 \%$ the rate of propionate. Most of this activity was attributed to PrpE since the control extract displayed only $8 \%$ activity (Table 2 ); butyrate was not a substrate for PrpE. The enzyme displayed high specificity for ATP. GTP, ITP, CTP and TTP failed to substitute for ATP in the reaction. The specificity for ATP contrasts to that of the acetyl-CoA synthetase (ADP-forming) activity of Pyrococcus furiosus, which can use GTP and ITP very effectively (Glasemacher $e t$ al., 1997). At present, we do not know if PrpE is an acylCoA (ADP-forming), or acyl-CoA (AMP-forming) synthetase. A careful analysis of the products of the PrpE reaction is necessary.

Reaction mixtures lacking $\mathrm{Mg}^{2+}$ showed $15 \% \operatorname{PrpE}$ activity, which was attributed to $\mathrm{Mg}^{2+}$ present in the 


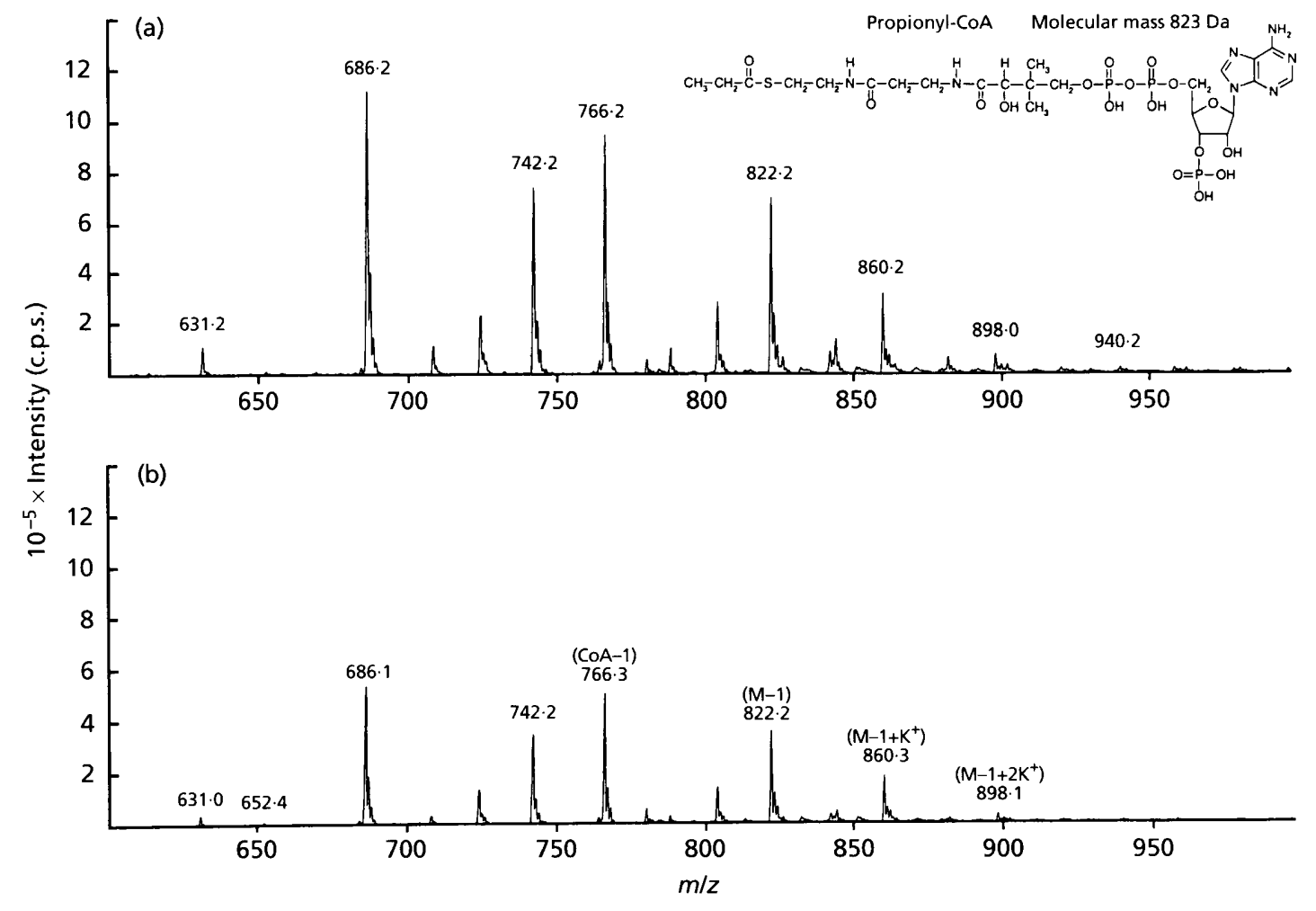

Fig. 3. Negative ion electrospray mass spectra of authentic propionyl-CoA (a), and of the product of the PrpE reaction (b). The inset in (a) shows the structure of propionyl-CoA. In both spectra the negative molecular ion was identified at $\mathrm{m} / \mathrm{z} 822$.

crude extracts. Consistent for the need for $\mathrm{Mg}^{2+}$, the propionyl-CoA synthetase activity of PrpE was sensitive to EDTA in the reaction mixture (data not shown).

\section{HPLC purification of PrpE product}

The PrpE product was purified by reverse-phase HPLC. The reaction product eluted as unresolved peaks from 39 to $44 \mathrm{~min}$ (data not shown), which were collected and analysed by MS. Authentic propionyl-CoA standard dissolved in $50 \mathrm{mM}$ phosphate buffer $\mathrm{pH} 7.5$ had the same elution profile, retention times and UV-visible spectrum when the acetonitrile/ammonium acetate solvent system was used (data not shown). The propionyl-CoA peak was not seen when cell-free extract of strain JE4287 (vector-only control) was substituted for cell-free extract of strain JE4184 (pT7-6 prp $E^{+}$) in the reaction mixture (data not shown). If the solvent system was changed to phosphate buffer with methanol (Corkey et al., 1981), both the product of the PrpE reaction and authentic propionyl-CoA eluted as a single peak (data not shown). This result suggested that multiple peaks observed in the acetonitrile/ammonium acetate solvent system were a mixture of different salts of the CoA moiety. The phosphate/methanol solvent system was not used due to difficulties in removing phosphate buffer from the PrpE product.

\section{MS of PrpE product}

Negative ion electrospray mass spectra were obtained for authentic propionyl-CoA and for the product of the PrpE-catalysed reaction (Fig. $3 a$ and b). The molecular mass of propionyl-CoA is $823 \mathrm{Da}$ at the neutral state. Fig. 3(a) shows the negative molecular ion $(\mathrm{M}-1)$ for authentic propionyl-CoA at $m / z 822 \cdot 2$. Peaks at $\mathrm{m} / \mathrm{z}$ $766 \cdot 2,860 \cdot 2$ and $898 \cdot 0$ were assigned to $\mathrm{CoA}-1$, the potassium salt of the negative molecular ion $\left(\mathrm{M}-1+\mathrm{K}^{+}\right)$and the di-potassium salt of the negative molecular ion $\left(\mathrm{M}-1+2 \mathrm{~K}^{+}\right)$, respectively. Two other prominent peaks $(m / z 742 \cdot 2$ and $m / z 686 \cdot 2)$ were presumed to be fragments of propionyl-CoA, but were not identified. Fig. 3(b) shows that the spectrum obtained for the HPLC-purified product of the PrpEcatalysed reaction displayed the same peaks. This result confirmed that propionyl-CoA was the product of the PrpE reaction.

\section{Implications of the amino acid sequence of PrpE}

Moyed \& Lipmann (1957) first reported propionyl-CoA synthetase activity in extracts of an unidentified soil bacterium. This paper reports the first identification of a gene encoding propionyl-CoA synthetase. In light of the homology of prpE to genes encoding acetyl-CoA synthetases, it is possible that genes annotated in 
databases as encoding acetyl-CoA synthetases in other organisms may actually encode propionyl-CoA synthetases. For example, according to BLASTP sequence analysis (Altschul et al., 1997), homologues in E. coli (GenBank accession no. U73857), Lysobacter (Y07914) and Pseudomonas putida (U24215) are 89, 58 and $54 \%$ identical to PrpE, respectively. However, Acs of E. coli (P27550) is only $37 \%$ identical to PrpE and 36-40\% identical to the PrpE homologues from E. coli, Lysobacter and P. putida. These differences raise the possibility that these homologues are likely to be propionate-specific acyl-CoA synthetases.

\section{ACKNOWLEDGEMENTS}

This work was supported by NSF grant MCB 9724924 and UW-Madison Graduate School project 970146 to J.C.E.-S. A.R.H. was supported by an NIH biotechnology training grant GM08349 and an NSF predoctoral fellowship. We thank A. J. Wolfe, S. R. Kushner and D. Downs for plasmids and strains. We thank Amy Harms of the Biotechnology Center of the University of Wisconsin-Madison for obtaining the mass spectra.

\section{REFERENCES}

Altschul, S. F., Madden, T. L., Schaffer, A. A., Zhang, J., Miller, W. \& Lipmann, D. J. (1997). Gapped BLAST and PSI-BLAST: a new generation of protein database search programs. Nucleic Acids Res 25, 3389-3402.

Ausubel, F. M., Brent, R., Kingston, R. E., Moore, D. D., Seidman, J. G., Smith, J. A. \& Struhl, K. (1989). Current Protocols in Molecular Biology, pp. 1.8.1-1.8.3; New York: Greene Publishing Associates \& Wiley-Interscience.

Bartolomé, B., Jubete, Y., Martínez, E. \& de la Cruz, F. (1991). Construction and properties of a family of pACYC184-derived cloning vectors compatible with pBR322 and its derivatives. Gene 102, 75-78.

Bochner, B. R., Huang, H.-C., Schieven, G. L. \& Ames, B. N. (1980). Positive selection for loss of tetracycline resistance. J Bacteriol 143, 926-933.

Brown, T. D. K., Jones-Mortimer, M. C. \& Kornberg, H. L. (1977). The enzymic interconversion of acetate and acetyl-coenzyme $\mathrm{A}$ in Escherichia coli. J Gen Microbiol 102, 327-336.

Chan, R. K., Botstein, D., Watanabe, T. \& Ogata, Y. (1972). Specialized transduction of tetracycline resistance by phage P22 in Salmonella typhimurium. II. Properties of a high transducing lysate. Virology 50, 883-898.

Corkey, B. E., Brandt, M., Williams, R. J. \& Williamson, J. R. (1981). Assay of short-chain acyl coenzyme A intermediates in tissue extracts by high-pressure liquid chromatography. Anal Biochem 118, 30-41.

Escalante-Semerena, J. C. \& Roth, J. R. (1987). Regulation of cobalamin biosynthetic operons in Salmonella typhimurium. J Bacteriol 169, 2251-2258.

Fellay, R., Frey, J. \& Krisch, H. (1987). Interposon mutagenesis of soil and water bacteria: a family of DNA fragments designed for in vitro mutagenesis of Gram-negative bacteria. Gene 52, 147-154.

Fox, D. K. \& Roseman, S. (1986). Isolation and characterization of homogeneous acetate kinase from Salmonella typhimurium and Escherichia coli. J Biol Chem 261, 13487-13497.

Gerike, U., Hough, D. W., Russell, N. J., Dyall-Smith, M. L. \& Danson, M. J. (1998). Citrate synthase and 2-methylcitrate synthase: structural, functional and evolutionary relationships. Microbiology 144, 929-935.

Glasemacher, J., Bock, A.-K., Schmid, R. \& Schönheit, P. (1997). Purification and properties of acetyl-CoA synthetase (ADPforming), an archaeal enzyme of acetate formation, and ATP synthesis from the hyperthermophile Pyrococcus furiosus. Eur J Biochem 244, 561-567.

Guzman, L.-M., Belin, D., Carson, M. J. \& Beckwith, J. (1995). Tight regulation, modulation, and high-level expression by vectors containing arabinose $\mathrm{P}_{\mathrm{BAD}}$ promoter. J Bacteriol 177, $4121-4130$.

Hamilton, C. M., Aldea, M., Washburn, B. K., Babitzke, P. \& Kushner, S. R. (1989). New method for generating deletions and gene replacements in Escherichia coli. J Bacteriol 171, 4617-4622.

Hammelman, T. A., O’Toole, G. A., Trzebiatowski, J. R., Tsang, A. W., Rank, D. \& Escalante-Semerena, J. C. (1996). Identification of a new prp locus required for propionate catabolism in Salmonella typhimurium LT2. FEMS Microbiol Lett 137, 233-239.

Horswill, A. R. \& Escalante-Semerena, J. C. (1997). Propionate catabolism in Salmonella typhimurium LT2: two divergently transcribed units comprise the prp locus at 8.5 centisomes, $p r p R$ encodes a member of the sigma-54 family of activators, and the prpBCDE genes constitute an operon. J Bacteriol 179, 928-940.

Hosokawa, Y., Shimomura, Y., Harris, R. A. \& Ozawa, T. (1986). Determination of short-chain acyl-coenzyme A esters by highperformance liquid chromatography. Anal Biochem 153, 45-49.

Kumari, S., Tishel, R., Eisenbach, M. \& Wolfe, A. J. (1995). Cloning, characterization, and functional expression of acs, the gene which encodes acetyl coenzyme A synthetase in Escherichia coli. J Bacteriol 177, 2878-2886.

Kunitz, M. J. (1952). Crystalline inorganic pyrophosphatase isolated from baker's yeast. J Gen Physiol 35, 423-450.

Laemmli, U. K. (1970). Cleavage of structural proteins during the assembly of the head of bacteriophage T4. Nature 227, 680-685.

Maloy, S. R. \& Nunn, W. D. (1981). Selection for loss of tetracycline resistance by Escherichia coli. J Bacteriol 145, 1110-1112.

Maruyama, K. (1982). Short-chain acyl-coenzyme A synthetases in Rhodopseudomonas sphaeroides. J Biochem 91, 725-730.

Moyed, H. S. \& Lipmann, F. (1957). Studies on the adenosine triphosphate-propionate reaction in extracts of an unidentified bacterium. J Bacteriol 73, 117-121.

O’Brien, K., Deno, G., Ostrovsky de Spicer, P., Gardner, J. F. \& Maloy, S. R. (1992). Integration host factor facilitates repression of the put operon in Salmonella typhimurium. Gene 118, 13-19.

Preston, G. G., Wall, J. D. \& Emerich, D. W. (1990). Purification and properties of acetyl-CoA synthetase from Bradyrbizobium japonicum bacteroids. Biochem J 267, 179-183.

Priefert, H. \& Steinbuchel, A. (1992). Identification and molecular characterization of the acetyl-coenzyme A synthetase gene $(a c o E)$ of Alcaligenes eutrophus. J Bacteriol 174, 6590-6599.

Rhie, H. G. \& Dennis, D. (1995a). The function of $a c k A$ and $p t a$ genes is necessary for poly(3-hydroxybutyrate-co-3-hydroxyvalerate) synthesis in recombinant $p h a^{+}$Escherichia coli. Can J Microbiol 41, 200-206.

Rhie, H. G. \& Dennis, D. (1995b). Role of $f a d R$ and ato C(Con) mutations in poly (3-hydroxybutyrate-co-3-hydroxyvalerate synthesis in recombinant $p h a^{+}$Escherichia coli. Appl Environ Microbiol 61, 2487-2492.

Ryu, J.-I. \& Hartin, R. J. (1990). Quick transformation of Salmonella typhimurium LT2. Biotechniques 8, 43-45. 
Sasse, J. (1991). Detection of proteins. In Current Protocols in Molecular Biology, pp. 10.6.1-10.6.8. Edited by F. M. Ausubel, R. Brent, R. E. Kingston, D. D. Moore, J. G. Seidman, J. A. Smith \& K. Struhl. New York: Wiley Interscience.

Schmieger, H. (1971). A method for detection of phage mutants with altered transduction ability. Mol Gen Genet 100, 378-381.

Schmieger, H. \& Bakhaus, H. (1973). The origin of DNA in transducing particles of P22 mutants with increased transduction frequencies (HT-mutants). Mol Gen Genet 120, 181-190.

Tabor, S. (1990). Expression using the T7 RNA polymerase/ promoter system. In Current Protocols in Molecular Biology, pp. 16.2.1-16.2.11. Edited by F. M. Ausubel, R. Brent, R. E. Kingston, D. D. Moore, J. G. Seidman, J. A. Smith \& K. Struhl. New York: Wiley Interscience.

Textor, S., Wendisch, V. F., De Graaf, A. A., Muller, U., Linder, M. I., Linder, D. \& Buckel, W. (1997). Propionate oxidation in
Escherichia coli: evidence for operation of a methylcitrate cycle in bacteria. Arch Microbiol 168, 428-436.

Tsai, S. P., Hartin, R. J. \& Ryu, J.-I. (1989). Transformation in restriction-deficient Salmonella typhimurium LT2. J Gen Microbiol 135, 2561-2567.

Van Dyk, T. K. \& LaRossa, R. A. (1987). Involvement of ack-pta operon products in $\alpha$-ketobutyrate metabolism in Salmonella typhimurium. Mol Gen Genet 207, 435-440.

Way, J. C., Davis, M. A., Morisato, D., Roberts, D. E. \& Kleckner, N. (1984). New Tn10 derivatives for transposon mutagenesis and for construction of lacZ operon fusions by transposition. Gene 32, 369-379.

Received 24 November 1998; revised 15 February 1999; accepted 5 March 1999. 